\title{
Meditação: uma estratégia de cuidado em saúde para estudantes universitários
}

\author{
Meditation: a health care strategy for university students \\ Meditación: una estrategia de atención sanitaria para universitarios
}

\section{Luísa Maria Schuh ${ }^{\mathrm{I}}$, Fernanda Beheregaray Cabral ${ }^{\mathrm{II}}$, Leila Mariza Hildebrandt ${ }^{\mathrm{II}}$ Susane Flores Cosentino ${ }^{\text {IV }}$, Isabel Cristina dos Santos Colomév}

\begin{abstract}
Resumo: Objetivos: desenvolver atividades meditativas com estudantes de uma universidade do noroeste gaúcho e analisar a percepção de estudantes universitários sobre a prática meditativa. Método: pesquisa-intervenção, de abordagem qualitativa. Realizaram-se 11 encontros para meditação, com participação de cinco estudantes, no período de abril a julho de 2019. Os dados produzidos mediante questionário com dados sociodemográficos e de saúde, observação não participante e entrevista aberta foram submetidos à análise temática. Resultados: a participação dos estudantes na meditação foi motivada pela curiosidade, dificuldade de concentração, estresse, irritação, ansiedade e nervosismo. A meditação mindfulness proporcionou aumento da concentração e foco para os estudos, melhorou a qualidade do sono e promoveu autoconhecimento e bem-estar subjetivo. Conclusão: a meditação mindfulness na Universidade foi importante à promoção da saúde mental, efetiva à minimização de estados de estresse e ansiedade e promoveu mudanças positivas na vida dos estudantes.
\end{abstract}

Descritores: Estudantes; Saúde Mental; Meditação; Terapias Complementares; Enfermagem

Abstract: Objectives: to develop meditative activities with students from a university in northwestern Rio Grande do Sul and to analyze the perception of university students about meditative practice. Method: researchintervention, with a qualitative approach. We accomplished 11 meditation meetings, with the participation of five students, from April to July 2019. The data produced through a questionnaire with sociodemographic and health data, non-participant observation and open interview were subjected to thematic analysis. Results: students' participation in meditation was motivated by curiosity, difficulty concentrating, stress, irritation, anxiety and nervousness. Mindfulness meditation provided increased concentration and focus for studies, improved sleep

\footnotetext{
I Enfermeira. Universidade Federal de Santa Maria/Campus Palmeira das Missões. E-mail: luisaschuh@hotmail.com.br ORCID ID: https://orcid.org/0000-0001-5450-2098

II Enfermeira. Doutora em Ciências. Professora Adjunta Universidade Federal de Santa Maria/Campus Palmeira das Missões. Palmeira das Missões, Rio Grande do Sul, Brasil. E-mail: cabralfernandab@gmail.com ORICID ID: https://orcid.org/0000-0002-4809-278X

III Enfermeira. Doutora em Ciências. Professora Adjunta Universidade Federal de Santa Maria/Campus. Palmeira das Missões, Palmeira das Missões, Rio Grande do Sul, Brasil. E-mail: leilahildebrandt@yahoo.com.br ORCID ID: https://orcid.org/0000-0003-0504-6166

IV Enfermeira. Doutora em Ciências. Professora Adjunta Universidade Federal de Santa Maria/Campus Palmeira das Missões. Palmeira das Missões, Rio Grande do Sul, Brasil. E-mail: susycosentino@hotmail.com ORCID ID: https://orcid.org/0000-0002-0998-0733

V Enfermeira. Doutora em Enfermagem. Professora Adjunta Universidade Federal de Santa Maria/Campus Palmeira das Missões. Palmeira das Missões, Rio Grande do Sul, Brasil. E-mail: enfbel@yahoo.com.br ORCID ID: https://orcid.org/0000-0001-7680-3289
} 
quality and promoted self-awareness and subjective well-being. Conclusion: mindfulness meditation at the University was important to promote mental health, effective in minimizing stress and anxiety states and promoted positive changes in students' lives.

Descriptors: Students; Mental Health; Meditation; Complementary Therapies; Nursing

Resumen: Objetivos: desarrollar actividades meditativas con estudiantes de una universidad del noroeste de Rio Grande do Sul y analizar la percepción de universitarios sobre la práctica meditativa. Método: investigaciónintervención con enfoque cualitativo. Se realizaron 11 encuentros de meditación, con la participación de cinco estudiantes, entre abril y julio de 2019. Los datos producidos mediante un cuestionario con datos sociodemográficos y sanitarios, observación no participante y entrevista abierta se sometieron al análisis temático. Resultados: la participación de los estudiantes en la meditación estuvo motivada por la curiosidad, dificultad para concentrarse, estrés, irritación, ansiedad y nerviosismo. La meditación mindfulness proporcionó una mayor concentración y enfoque para los estudios, mejoró la calidad del sueño y promovió la autoconciencia y el bienestar subjetivo. Conclusión: la meditación mindfulness en la Universidad fue importante para promover la salud mental, eficaz para minimizar los estados de estrés y ansiedad y promovió cambios positivos en la vida de los estudiantes. Descriptores: Estudiantes; Salud Mental; Meditación; Terapias Complementarias; Enfermería

\section{Introdução}

O ingresso na universidade significa o término de um ciclo e o ingresso naquele que o conduzirá à vida profissional. Para alguns, a necessidade de adaptação às demandas da vida universitária pode afetar o seu desempenho acadêmico, ser geradora de crise e, por vezes, de processos de adoecimento. ${ }^{1-2}$ Estudo sobre depressão em estudantes dos cursos de Biomedicina, Educação Física, Enfermagem e Farmácia de uma universidade pública do Mato Grosso identificou tendência à depressão em $41 \%$ dos universitários, com maior ocorrência no curso de Enfermagem (55\%). O mesmo estudo sinalizou prevalência significativa dessa tendência à depressão em estudantes do sexo feminino cursando as séries iniciais. ${ }^{1}$ Outra pesquisa sobre as manifestações de ansiedade em estudantes de Enfermagem destaca que os discentes apresentam tais sintomas no decorrer do curso, o que pode interferir na sua formação profissional. ${ }^{2}$

Ao encontro desse estudo, estratégias que colaborem na minimização de desgastes dos estudantes a exemplo da escuta, acolhimento, apoio e meditação, dentre outras, são importantes na universidade. Nessa direção, pesquisa identificou que a aproximação entre docentes e discentes, em que o professor mantenha postura mobilizadora, motivadora e de incentivo às 
3 | Schuh LM, Cabral FB, Hildebrandt LM, Cosentino SF, Colomé ICS

atividades propostas, pode se constituir em estratégia que viabilize a escuta e o acolhimento dos estudantes, minimizando, assim, a ansiedade. ${ }^{2}$

Essa problemática requer atenção das Instituições de Ensino Superior (IES) que devem incluir, entre seus programas e políticas de assistência estudantil, ações que visem a promoção da saúde física e mental dos universitários e, consequentemente, melhorar sua qualidade de vida. Isso se justifica, pois, a fase universitária pode ser marcada por algumas dificuldades, sendo elas acadêmicas, interpessoais e pessoais, o que requer que as IES construam estratégias de intervenções assistenciais de cuidados em saúde aos seus estudantes. ${ }^{1-2}$

Nesse sentido, a meditação pode ser uma intervenção benéfica ao estudante, uma vez que sua prática envolve um tipo de treinamento que busca desenvolver e aprimorar habilidades mentais, cognitivas e emocionais, o que contribui para o desempenho mais eficiente, tanto no que tange a aspectos intra como interpessoais, e um viver com mais qualidade e saúde. ${ }^{3} \mathrm{~A}$ palavra meditação, origina-se do sânscrito, língua tradicional da Índia, que significa atenção, contemplação, e expressa a prática de meditar. Ela tem a capacidade de produzir conexão entre a mente, o corpo e o espírito, provocando alterações estruturais em áreas cerebrais que favorecem a melhoria das funções cognitivas e emocionais da pessoa. ${ }^{4}$

Há várias técnicas de meditação, sendo as mais conhecidas e utilizadas no Ocidente a meditação transcendental, mindfulness, zen e a vipassana. ${ }^{4-5}$ A mindfulness ou "atenção plena”, prática meditativa adotada neste estudo, consiste em treinar capacidades de autorregulação e controle atencional da experiência no momento presente. Essa técnica se constitui em um treinamento que reúne vários métodos, a exemplo de respiração focada, consciência corporal, meditação, e promove um profundo estado de calma e de concentração no momento presente, com foco no próprio corpo e mente. ${ }^{6} \mathrm{O}$ treinamento regular de habilidades de mindfulness pode reduzir a reatividade emocional, o estresse, a ansiedade, a depressão e outras emoções negativas, 
além de aprimorar a capacidade de autorregulação, de metacognição, inteligência emocional e bom estado físico e emocional. ${ }^{4-6}$

O Ministério da Saúde incentiva a utilização das Práticas Integrativas e Complementares (PICs) no âmbito do Sistema Único de Saúde (SUS), mediante a Política Nacional de Práticas Integrativas e Complementares (PNPIC). Ela estabelece, em suas diretrizes, a meditação como uma prática que aborda o ser humano de modo integral e relaciona as dimensões física, emocional, mental e espiritual para curar doenças e promover a plenitude da saúde e um viver com mais qualidade. ${ }^{7}$

Este estudo tem como objeto a prática de meditação destinada a um grupo de estudantes de uma universidade pública no noroeste gaúcho. A preocupação com a saúde de universitários se justifica, pois, frequentemente há manifestações físicas e psicológicas, expressas por estudantes universitários, decorrentes das mudanças e responsabilidades que essa etapa da vida conduz, as quais podem afetar negativamente o desempenho nos estudos, as relações interpessoais e a saúde. ${ }^{1-2}$ A meditação mindfulness é uma intervenção potente que pode contribuir para a promoção da saúde desses estudantes. Nessa direção, a questão de pesquisa delineada foi: Qual a percepção de estudantes universitários sobre a prática meditativa? O estudo teve como objetivos desenvolver atividades meditativas com estudantes de uma universidade do noroeste gaúcho e analisar a percepção de estudantes universitários sobre a prática meditativa.

\section{Método}

Estudo qualitativo, do tipo pesquisa-intervenção, no qual o pesquisador trabalha explicitamente com, para e por pessoas, ao invés de estudar sobre elas, com foco maior na geração de soluções para problemas do cotidiano. Esse método de pesquisa analisa os efeitos das práticas no cotidiano institucional, desconstruindo territórios e facultando a criação de novas práticas. ${ }^{8}$ 
O estudo foi realizado nas dependências do Campus de uma universidade pública do noroeste gaúcho que sedia os cursos de Administração, Ciências Biológicas, Ciências Econômicas, Enfermagem, Nutrição e Zootecnia, no período de abril a julho de 2019. Os critérios de inclusão dos participantes foram ter mais de 18 anos de idade, ser estudante da instituição, estar matriculado no $1^{\circ}$ semestre letivo de 2019 e expressar disposição para participar do grupo de meditação. Os estudantes, dos diversos cursos e semestres, foram convidados pela pesquisadora, em visitas às salas de aula para apresentação da proposta, e pela sua divulgação em folders informativos sobre o grupo de meditação fixados nas dependências do Campus.

Participaram da pesquisa cinco estudantes. Realizaram-se 11 encontros semanais para prática de meditação mindfulness, com duração de 1 hora cada. Considerando-se as 15 semanas do semestre letivo e o período necessário ao planejamento e divulgação da proposta, estabeleceram-se 11 encontros para meditação em função de a mindfulness ser uma intervenção que requer treinamento de habilidades por parte da pessoa que a media. Portanto, o número de encontros se definiu pela finalização do semestre letivo já que os estudantes, ao encerrarem as atividades acadêmicas, dirigem-se aos seus locais de moradia.

A meditação mindfulness foi guiada por uma das autoras, estudante do 9º $^{\circ}$ semestre do curso de Enfermagem, a qual realizou previamente instrumentalização para tal. Os dados foram produzidos por estratégias híbridas, com múltiplas fontes de evidência trianguladas que abrangeram: questionário com questões sociodemográficas e de saúde, respondido no primeiro encontro grupal; observação não participante das práticas meditativas registrada em diário de campo por um auxiliar de pesquisa; entrevista aberta, não estruturada, gravada e transcrita pela pesquisadora, realizada ao final dos 11 encontros, com questões sobre a percepção dos participantes sobre as práticas de meditação mindefulness realizadas.

As atividades meditativas foram iniciadas com a recepção dos participantes pela pesquisadora. Após esse momento de acolhimento, alguns estudantes sentavam-se em cadeiras 
Meditação: uma estratégia de cuidado em saúde para estudantes universitários | 6

com as costas apoiadas e outros se deitavam em colchonetes para o início da prática. A meditação foi guiada por áudios ou pela pesquisadora, que utilizava palavras proferidas para conduzir o relaxamento corporal e mental. Também foram incentivados à respiração consciente e visualizações criativas convergentes aos temas de cada encontro, tais como gratidão, paz, bemestar físico, saúde mental e emocional, dentre outros. Todas as vivências partilhadas pelos participantes em relação às práticas meditativas e suas manifestações subjetivas foram captadas pela observadora e registradas em diário de campo.

Para preservar a identidade dos participantes, ao final das falas, os mesmos foram identificados pela letra 'E' de estudantes, seguida de números de 1 a 5 . O registro das observações no diário de campo foi precedido pela identificação: Nota do Diário de Campo (NDC), sucedido de Prática de Meditação (PM) e dos números de 1 a 11 relativos aos encontros desenvolvidos.

Os dados empíricos produzidos no trabalho de campo foram submetidos à técnica de análise temática, a qual possibilita a identificação de conteúdos manifestos da fala das participantes em seu contexto social e histórico, operacionalizada por meio dos seguintes passos: pré-análise; exploração do material; tratamento dos resultados obtidos; e interpretação. Na pré-análise, realizou-se a transcrição das entrevistas gravadas, seleção e sistematização das ideias iniciais e releitura do material produzido, o que favoreceu a visão geral dos dados produzidos, de modo a atender aos critérios de validação dos temas emergentes, tais como exaustividade, representatividade, homogeneidade e pertinência. $\mathrm{Na}$ sequência, os dados empíricos produzidos foram classificados, categorizados e interpretados de modo articulado ao referencial teórico em resposta aos objetivos do estudo. ${ }^{9}$

A pesquisa foi aprovada pelo Comitê de Ética em Pesquisa da Universidade Federal de Santa Maria em 22/03/2019, com o parecer $n^{\circ} 3.215 .383$, e todos os participantes assinaram o Termo de Consentimento Livre e Esclarecido em conformidade com a Resolução no 466 do Conselho Nacional de Saúde. 


\section{Resultados e Discussão}

\section{Características sociodemográficas e de saúde}

Dos cinco participantes, quatro eram do sexo feminino e um do sexo masculino, com idades entre 18 e 23 anos, solteiros e se reconheceram como de cor da pele branca. Todos foram egressos de escola pública, onde cursaram o ensino médio. Destes, três eram estudantes do curso de Nutrição e dois de Enfermagem, entre o segundo e sétimo semestre. A partir de 2004, houve a expansão do ensino superior no País, mediante programas e políticas públicas de democratização e universalização do acesso a essas instituições, com destaque para a Lei n⿳0 12.711, que institui a reserva de cotas nas universidades federais para alunos oriundos de escolas públicas. ${ }^{10}$

Dois estudantes responderam que não estavam trabalhando no período da pesquisa, outros dois trabalhavam até 20 horas semanais e um trabalhava eventualmente. Quanto à situação financeira, dois não possuíam renda e seus gastos eram custeados pela família e/ou por outras pessoas; outros dois possuíam renda, mas também recebiam ajuda financeira da família e/ou de outras pessoas; e um tinha seus gastos pessoais financiados por programas governamentais na modalidade de bolsa. Pesquisa com estudantes de Enfermagem cujo objetivo foi analisar a associação entre a presença de estresse e vulnerabilidades sociodemográficas e acadêmicas demonstrou que a experiência do estresse foi maior naqueles que necessitavam trabalhar para custear os estudos, com 3,14 mais chances de desenvolver estresse, quando comparados àqueles que não precisavam trabalhar. ${ }^{11}$

Quando questionados sobre o significado de estudar, para quatro participantes era uma forma de crescimento pessoal, enquanto para um, adquirir conhecimentos. Quanto à rotina de estudos extraclasse, três responderam que estudavam em dias alternados e dois diariamente, sendo que três dedicavam de uma a três horas semanais para os estudos e dois de oito a doze horas. Foi consenso entre eles de que estudar sozinho era melhor. Sobre o hábito de ler livros, revistas, jornais e/ou outros, todos responderam que liam livros. Já em relação aos meios de 
Meditação: uma estratégia de cuidado em saúde para estudantes universitários | 8

comunicação mais utilizados para se manterem informados, a internet foi unânime entre os participantes. Quanto ao tempo destinado ao uso de redes sociais (Facebook, Instagram, Whats $A p p$ ), quatro responderam de duas a quatro horas por dia e um de seis a oito horas diárias.

Dois estudantes disseram que, muitas vezes, sentiam-se sozinhos, um algumas vezes e outro raramente. Sobre a rede de apoio acessada para o enfrentamento de dificuldades durante a graduação, para três estudantes, os colegas de curso e/ou amigos foram os mais destacados, um mencionou os pais e outro referiu não ter recebido nenhum tipo de apoio nessas situações. Em relação à saúde, dois estudantes a consideraram como boa, outros dois como razoável e um a classificou como muito boa. Todos responderam que não possuíam doença crônica, somente um estudante fazia uso contínuo de medicamentos, e apenas um praticava atividades físicas. Acerca da alimentação diária, três estudantes a consideraram boa e um avaliou esse quesito como ruim.

Estudo sobre sintomas depressivos em estudantes da área da saúde de uma universidade pública assinala que aspectos sociais, econômicos, acadêmicos e os hábitos de saúde estão entre os fatores que podem influenciar o desenvolvimento de sintomas comuns de depressão nessa população. Elementos como hábitos de vida saudáveis, momentos destinados à atividade física e ao lazer e bons relacionamentos sociais e afetivos são promotores à saúde mental e física do estudante. ${ }^{12}$ Ainda, sobre dificuldade para dormir, três estudantes relataram que algumas vezes a tiveram, um informou que sempre tinha e, para um, isso nunca aconteceu. Quanto ao uso de drogas lícitas ou ilícitas, três responderam que usavam bebida alcoólica, na frequência de uma vez ao mês, um fazia uso uma vez na semana e outro apenas em evento festivo. Nenhum dos participantes referiu uso de outras substâncias psicoativas.

\section{Meditação: uma estratégia de cuidado em saúde para estudantes universitários}

$\mathrm{Na}$ ótica dos estudantes, a meditação mindfulness foi reconhecida como uma prática que promove maior autoconhecimento, estado de clareza mental e espiritual, bem-estar e emoções 
9 | Schuh LM, Cabral FB, Hildebrandt LM, Cosentino SF, Colomé ICS

positivas. Também favorece o relaxamento corporal, ameniza angústias e ansiedades, além de melhorar a concentração e a qualidade do sono.

Além dos benefícios pelas alterações positivas no humor e no desempenho cognitivo, a meditação também proporciona processos de transformação pessoal, por meio de experiências de ordem subjetiva, com desenvolvimento e/ou ampliação de potencialidades humanísticas que podem favorecer sensações de bem-estar, harmonia, de crescimento e satisfação pessoal e paz.,7,13

A curiosidade sobre a prática da meditação, dificuldade de concentração e ansiedade foram alguns dos motivos que mobilizaram os participantes a aderir ao grupo de meditação.

Já tinha ouvido falar e tinha muita curiosidade sobre o que era feito e como a gente se sentia. Todo mundo falava que a gente ficava mais leve, se concentrava e, às vezes, não tenho muita concentração, sou muito ansiosa. (E1)

Sou uma pessoa que tem que pensar mais no presente, e não me preocupar muito com o futuro, com o que vai acontecer amanhã. Agora, penso mais em mim e no que estou fazendo, é isso que me importa. (E3)

No decorrer dos encontros para meditação mindfulness, os participantes comentavam entre si que percebiam aumento significativo da concentração nas atividades do dia a dia (NDC: PM5; PM7). Outros motivos que estimularam os estudantes a participar do grupo de meditação foram estresse, irritação, ansiedade, nervosismo, necessidade de autoconhecimento, de paciência e de concentração.

Era muito brava, estressada, qualquer coisa me irritava! Procurei me encontrar mais, ficar comigo, me acalmar, eu como espírito. A meditação envolve mais que só o ato. Entrei no grupo para ter conhecimento, conhecer pessoas. (E2)

Sempre soube que a meditação era uma coisa que acalmava e trazia muitos benefícios. Foi isso que fui buscar no grupo, uma forma de trazer calma e paciência à vida, porque sou muito ansioso. Penso muito no que vai vir depois, no futuro. (E3) 
Desde uma perspectiva ampliada do sujeito, a meditação evidencia a união corpo-menteespírito, ultrapassando os pressupostos do paradigma biomédico cuja ênfase nos aspectos biológicos confere materialidade ao corpo como objeto principal de análises e intervenções. Pesquisas acerca dos benefícios da meditação destacam que o treinamento sistemático da atenção é desenvolvido por meio de técnicas capazes de gerar respostas física, mental e psicológica que favoreçam a prática de autorregulação do corpo e da mente e auxiliem na prevenção do estresse, no controle de problemas de saúde já estabelecidos, bem como na promoção da saúde mental. ${ }^{14-15}$ Estudo internacional que avaliou a efetividade de um programa de treinamento de mindfulness para estudantes universitários destacou mudanças percebidas em relação ao estresse e melhorias significativas na qualidade do sono, atenção plena e compaixão. ${ }^{16}$

Geralmente, o ingresso no ensino superior implica em um processo de transição para a vida adulta e exige do estudante mudanças e adaptações para o enfrentamento de desafios da vida acadêmica, os quais podem ser fontes de estresse, como competitividade, atividades avaliativas, desenvolvimento de competências e habilidades técnicas para o exercício profissional. Nesse sentido, estudos apontam que as perturbações mentais, como o estresse, a ansiedade e a depressão, em estudantes do ensino superior, provocam má qualidade do sono, bem como associação com consumo de álcool. ${ }^{2,17}$

Nas vivências grupais, observou-se atenção à respiração profunda, maior relaxamento, calma e mais conexão interna com a prática meditativa. Um participante relatou que sua vida está mais tranquila, o que tem contribuído para o seu autoconhecimento (NDC: PM7; PM10; PM11). Outro destaque foi a prática de meditação mindfulness como uma ferramenta de incentivo e apoio às mudanças.

[...] tu se "mata” estudando, mas não vai adiantar, não vou conseguir, eu não consigo! Com a meditação, tu tens, na verdade, uma palavra de apoio, 
11 | Schuh LM, Cabral FB, Hildebrandt LM, Cosentino SF, Colomé ICS

de incentivo. Então, muda a mentalidade, o jeito de ver aquela situação. (E2)

Pesquisa sobre ansiedade e consumo de ansiolíticos por estudantes de Enfermagem destaca a necessidade de estratégias para minimizar esses estados de desconforto e recomenda às instituições de ensino medidas direcionadas à redução de fatores de risco para a ansiedade, revisão de metodologias e adoção de novas práticas pedagógicas, além de estratégias que viabilizem a escuta e acolhimento dos estudantes. ${ }^{18}$

No encontro grupal que tratou da temática emoções, a meditação foi guiada com foco no sentimento de gratidão para favorecer mudanças e elevações relativas a esse campo vibracional. Ao seu término, os estudantes partilharam sensações e vivências que emergiram, as quais foram reconhecidas pela maioria como positivas (NDC: PM2).

Para aqueles que meditaram individualmente em suas residências, a prática grupal foi reconhecida como melhor. Também foi assinalada a importância da ambiência, visto que locais adequados e silenciosos oportunizam a sua prática. Outro aspecto destacado foi de que a meditação em grupo favoreceu a sua regularidade.

Tentei fazer em casa, mas não consegui me concentrar tanto quanto aqui [no grupo]. Porque lá [em casa] tem bastante movimento. [no grupo]. Eu me concentrava muito, mas em casa não conseguia me concentrar. (E1)

Eu já tentava fazer sozinha [meditação], mas não conseguia. Em grupo fortaleceu e foi bem melhor. (E5)

Com relação à assiduidade no grupo de meditação, esta variou de nove a onze encontros por participante e todos passaram a praticar a meditação em outros momentos, para além dos encontros grupais, como demonstra um estudante:

Comecei a fazer meditação em casa, geralmente quando ia dormir ou quando estava mais agitada, nervosa. Fazia e surtia efeito, conseguia relaxar, ficar mais calma e dormir bem, porque algumas vezes tinha insônia. (E4) 
Os estudantes se consideravam pessoas ansiosas e/ou nervosas antes de ingressarem no grupo de meditação, conforme indicam os depoimentos:

Ansiosa, sim. Todos falam que sou nervosa, mas eu não acho! Quando tem prova ou algum trabalho para fazer, até que não faça, não paro de pensar nisso. Pode faltar uns três dias, mas tenho que fazer para ficar tranquila. (E1)

Não tinha nem paciência para estar no grupo de meditação. Antes, tentei fazer uma ou duas vezes. Não tinha paciência para meditar e, agora, tenho prazer em fazer meditação. (E4)

Para a maioria dos participantes, a prática da meditação foi benéfica para a melhora desses aspectos:

Agora eu faço respiração, acho que está me ajudando, tem que continuar as meditações, pela ansiedade, ajudou bastante. (E1)

Quando tu vais ficar estressado, lembra de alguma palavra que ouviu na meditação, dá uma respirada e vai praticar. (E2)

Não tenho mais aquela agitação que tinha, chegava a ter pânico de estar em lugar, dava tontura, parece que subia um calor e passava mal. Agora, não tenho mais isso, depois que comecei a fazer meditação. (E4)

Um estudante com crises de enxaqueca destacou que a prática da meditação foi benéfica especialmente nos momentos de dor:

$\mathrm{Na}$ meditação, muitas vezes, estava [com enxaqueca], mas quando estávamos fazendo a prática, não pensava naquilo e não sentia dor. Ali, no momento, esquecia de tudo, isso era muito bom. (E1)

Outra participante destacou que a meditação, entre outras atividades, foi importante para abolir o uso de medicações psicotrópicas:

Tomava medicações ansioliticas e antidepressivas [antes de ingressar na prática de meditação]. A meditação entrou mais constante na minha vida, às vezes, vou na aula de biodanza, tento fazer exercícios físicos, cuidar da alimentação, muitas mudanças positivas. (E5) 
Para corroborar, pesquisa sobre ansiedade e consumo de ansiolíticos entre estudantes de Enfermagem apontou nervosismo, insônia, estresse, presença de ansiedade e depressão, enxaquecas e hospitalizações como os principais motivos para o consumo dos ansiolíticos, dados semelhantes aos indicados pelos participantes desta investigação. ${ }^{18} \mathrm{O}$ elevado consumo de substâncias psicoativas e psicofármacos e altos níveis de depressão nos estudantes da pesquisa citada evidenciou a necessidade de maior atenção ao consumo desses medicamentos, bem como de intervenções que visem à promoção da saúde mental dos estudantes, prevenção de ansiedade e depressão, melhora da autoestima, incentivo à autonomia e desenvolvimento de habilidades para resolução de problemas. ${ }^{18}$

Pesquisa que avaliou os efeitos de um curso de meditação em estudantes de Enfermagem, Medicina e Fonoaudiologia de uma universidade pública de São Paulo/Brasil, identificou efeitos benéficos especialmente na redução da ansiedade e diminuição de sentimentos negativos, principalmente do medo e da hostilidade. Ainda, os participantes do referido curso de meditação tomaram consciência de suas emoções e reconheceram a importância de saber lidar com as mesmas. ${ }^{19}$

Como estratégia para enfrentamento da problemática posta, destaca-se que a meditação melhora a saúde, a qualidade de vida e o bem-estar dos praticantes, repercutindo positivamente no enfrentamento das dificuldades diárias e no manejo do estresse. Foi consenso entre os participantes de que a meditação proporciona mais foco e tranquilidade para os estudos, especialmente antes de atividades avaliativas, como destacou um estudante:

Não me estresso mais com provas, estudo tranquilo, não tenho mais aquela pressão que eu tinha antigamente. (E4)

A aquisição de habilidades intelectuais e o desempenho dos alunos podem ser afetados pela ansiedade, pois esse estado é capaz de interferir nos aspectos cognitivos dos acadêmicos e, até mesmo, afetar o raciocínio e o aprendizado. ${ }^{18}$ 
Meditação: uma estratégia de cuidado em saúde para estudantes universitários | 14

Com o andamento dos encontros grupais, o treinamento e o melhor engajamento na prática de mindfulness, os estudantes relataram benefícios diretos da meditação na sua rotina de vida, tais como: melhor manejo de dificuldades relativas à concentração para estudar, aumento de atenção, foco no momento presente e consciência plena, redução de estresse e ansiedade. A prática de mindfulness incentiva a pessoa a assumir papel ativo na responsabilização pela sua vida e saúde, mediante mudanças cerebrais chamadas de neuroplasticidade e regulação de estados mentais que melhoram a capacidade cognitivoemocional, gerando novos padrões comportamentais que promovam melhora no bem-estar e um viver com mais qualidade. ${ }^{6}$

$\mathrm{Na}$ mesma direção, a meditação mindfulness favorece a criatividade, o aumento da atenção e da concentração em estudantes, melhora o desempenho e as habilidades socioemocionais, bem como sintomas de ansiedade e a qualidade de vida, o que contribui significativamente para a saúde mental dos seus praticantes..$^{20-21}$ Destaca, ainda, o potencial da prática da mindfulness pela Enfermagem na prevenção e tratamento de problemas decorrentes do estresse, no seu autocuidado, bem como no cuidado aos usuários e seus familiares. ${ }^{21}$

Alguns estudantes citaram mudanças que ocorreram no seu dia a dia a partir da prática de meditação, tais como maior consciência e entendimento sobre suas vivências, flexibilidade e autoaceitação, conforme os relatos dos depoimentos a seguir:

Ser mais flexível, ver o lado bom. Procurar saber o que está acontecendo, o que está me deixando brava, o que não está dando certo [...] calma, autoconfiança. Claro que é uma construção, não é de uma hora para outra, mudou bastante. (E2)

Era uma pessoa muito negativa, tudo o que ia fazer não ia dar certo. Não que não tenha mais esse tipo de pensamento, mas diminuiu. Consigo me policiar, perceber as coisas e agir com mais calma. (E4)

A meditação nos torna mais conscientes, se priorizar, refletir antes de tomar decisões, traz mais autoconhecimento. Essa questão de entender os 
15 | Schuh LM, Cabral FB, Hildebrandt LM, Cosentino SF, Colomé ICS

processos do universo da nossa vida. Entender que a gente não tem controle sobre tudo. (E5)

As práticas corporais e meditativas envolvem o autoconhecimento, o exercício do protagonismo, a responsabilidade e a autonomia no cuidado de si, o que contribui para maior integração entre razão, intuição e sentidos dos seus praticantes. ${ }^{22}$ As mudanças elencadas pelos participantes são favorecidas pela prática de mindfulness cujo objetivo é manter a consciência no momento presente. Esse estado de presença é considerado positivo e possui associação com indicadores de saúde mental, tais como níveis elevados de afetos positivos, satisfação com a vida, vitalidade, regulação emocional e, também, menores níveis de ansiedade e depressão. ${ }^{20-21}$

Em um dos encontros, alguns participantes expressaram que seus pensamentos os levaram a vários lugares, mobilizando sensação de paz interior (NDC: PM1). A relação entre frequência vibracional e saúde mental foi o tema de um dos encontros grupais que associou a prática de meditação mindfulness e afirmações positivas. Após essa vivência, a pesquisadora instigou os estudantes para que substituíssem palavras, sentimentos e emoções negativos por outros de caráter positivo. Isso foi reconhecido como um exercício produtor de sensações de alívio, bem-estar e paz de espírito (NDC: PM3).

Pesquisa com estudantes de Medicina que avaliou os efeitos psicológicos após um programa de intervenção "mente-corpo", com 11 semanas de duração, que combinou yoga, meditação e técnicas de neurociência, destacou como resultados mais consciência corporal, com ênfase na sensopercepção (sensações físicas e emocionais), escuta atenta e melhorias na qualidade do sono e na condição de saúde com melhor capacidade de gerenciar estados de estresse. ${ }^{23}$

Para os estudantes, a prática meditativa em grupo favoreceu a concentração, a partilha de vivências e foi mais efetiva que a individual.

Em casa não conseguia me concentrar tanto, ali [no grupo] eu já conseguia mais, tirava o tempo para isso. (E1) 
Meditação: uma estratégia de cuidado em saúde para estudantes universitários | 16

A troca de ideias, de experiências sobre o que cada um sentia durante a meditação. Às vezes, o que um sentia era a mesma coisa que eu, outras era uma experiência diferente. (E2)

Sozinho é mais difícil concentrar para meditar! Em grupo, acho que permite maior concentração. Nas primeiras [práticas], tinha dificuldade para me concentrar. No final, fui conseguindo não pensar mais em outras coisas, fugir do pensamento. Mas, ainda tenho um pouco de dificuldade em me concentrar totalmente na meditação. (E3)

Ao longo dos encontros para meditação, alguns participantes relatavam que se sentiam relaxados, motivados e acolhidos no e pelo grupo, motivo pelo qual os próximos encontros eram aguardados com expectativa (NDC: PM1; PM3; PM11). A meditação mindfulness foi reconhecida como efetiva para a minimização de estados de estresse e ansiedade e mudanças na forma de andar a vida, não só dos participantes, mas também experimentada inclusive por alguns familiares.

Eu indicaria como uma ferramenta para mudar o teu olhar perante algumas coisas. Não só para nervosismo e ansiedade, mas para quem quer melhorar em todos os sentidos, vamos dizer uma descoberta. (E2)

Ela [avó] achou bom, porque não consegue dormir. Ela [avó] disse que relaxou bastante. (E1)

Apesar de dificuldades iniciais para a prática da meditação, um grupo de adolescentes destacou que esta produziu mudanças significativas, especialmente em relação ao humor, o que contribuiu para melhoria da qualidade de vida. ${ }^{24}$ Os estudantes destacaram a importância da prática da meditação mindfulness na Universidade para a promoção da saúde mental e indicaram a necessidade da continuidade do grupo de meditação.

Em um município pequeno, a gente não vê tanto a meditação. [A Universidade] é um lugar que estou quase sempre, estava procurando a mudança, e foi a oportunidade que alavancou mais ainda meu autoconhecimento. (E2) 
Adorei a iniciativa desse grupo, porque a ansiedade e o nervosismo estão cada vez mais presentes no cenário acadêmico. Deve ter mais momentos assim, foi muito lindo! Deve continuar no próximo semestre para os próximos alunos. (E3)

É algo tão bom e é de graça, vai da gente querer e buscar. Foi muito bom, a meditação muda vidas. (E5)

O período de formação universitária é uma etapa determinante para o futuro profissional, podendo ser atravessada por contextos de vulnerabilidade, cuja vivência pode gerar estresse, afetar a saúde mental e produzir situações de adoecimento de estudantes, o que requer atenção por parte das instituições de ensino. Como estratégias para o enfretamento dessa problemática, estudo destaca a relevância de programas institucionais ou ações direcionadas à promoção da saúde mental dos estudantes. ${ }^{17}$

A meditação mindfulness é uma tecnologia de cuidado de baixo custo financeiro que pode estar na vida de qualquer pessoa que se propõe a experienciá-la e está associada à melhoria na qualidade de vida. Esta pode ser praticada em diferentes cenários, como na família, no trabalho e nas instituições de ensino, desconstruindo a ideia que circula no imaginário social de que a meditação só pode ser praticada por grupos ou comunidades alternativas que partilham de sua filosofia.

O contexto universitário pode ser produtor de situações desgastantes para os estudantes em função de modificações no seu cotidiano e da necessidade de adaptações a momentos vivenciados pelo distanciamento da família e de amigos, questões econômicas e demandas específicas do mundo acadêmico. Essa conjuntura pode ser geradora de crise situacional e, também, de adoecimento. Desse modo, ressalta-se a importância de as IES desenvolverem estratégias assistenciais de acolhimento e de promoção à saúde física e mental desses estudantes. A prática da meditação mindfulness pode se constituir em uma ferramenta de ajuda aos acadêmicos, contribuindo para que a fase universitária seja vivenciada de maneira mais positiva.

Apesar da incipiência dessa experiência, o estudo apresenta como fatores limitantes o fato de ter sido realizado com um número pequeno de estudantes, em um único Campus Universitário. 
Meditação: uma estratégia de cuidado em saúde para estudantes universitários | 18

\section{Conclusão}

Este estudo teve como objetivo a realização de práticas meditativas grupais que se configuram como ferramenta efetiva para a minimização de estados de estresse e ansiedade, além de mudanças na vida de estudantes universitários. A curiosidade acerca da meditação, dificuldade de concentração, estresse, irritação, ansiedade e nervosismo foram elementos mobilizadores para a participação estudantil na prática meditativa.

Tendo em vista as dificuldades vivenciadas pelos estudantes na fase universitária, repleta de mudanças, conflitos e situações desafiadoras, o grupo de meditação foi uma iniciativa inovadora no Campus Universitário e se mostrou importante para sensibilizar a comunidade acadêmica para o sofrimento psíquico e seus impactos na saúde de estudantes.

Na lógica do cuidado integral e da humanização da saúde, princípios basilares do SUS, nos quais a Enfermagem como prática social se ancora, a meditação mindfulness, no cenário universitário, configura-se como potente estratégia de cuidado à saúde. Desse modo, a prática grupal meditativa, com ênfase na corresponsabilização pelo autocuidado em saúde, foi promotora de saúde mental, na medida em que proporcionou mais concentração e foco para os estudos, favoreceu o relaxamento corporal, melhorou a qualidade do sono e promoveu autoconhecimento, estado de clareza mental, espiritual e bem-estar dos participantes.

Os resultados do estudo sinalizam para a importância de novas ações dessa natureza, que visem ao cuidado em saúde da comunidade acadêmica em âmbito institucional. Assinala-se a pertinência da inclusão contundente das PICS na formação profissional como estratégia promotora de saúde. Destaca-se o potencial da Enfermagem na prática meditativa mindfulness, tendo em vista perspectivas acolhedoras e integrais na produção do cuidado em saúde como encontro de subjetividades. 
19 | Schuh LM, Cabral FB, Hildebrandt LM, Cosentino SF, Colomé ICS

\section{Referências}

1. Mesquita AM, Lemes AG, Carrijo MVN, Moura AAM, Couto DS, Rocha EM, et al. Depressão entre estudantes de cursos da área da saúde de uma universidade em Mato Grosso. J Health NPEPS [Internet]. 2016 [acesso em 2020 maio 25];1(2):218-30. Disponível em: https://periodicos.unemat.br/ index.php/jhnpeps/article/view/1433

2. Pereira FLR, Medeiros SP, Salgado RGF, Castro JNA, Oliveira AMN. Manifestações de ansiedade vivenciadas por estudantes de enfermagem. Rev Pesqui Cuid Fundam. 2019;11(4):880-6. doi: 10.9789/21755361.2019.v11i4.880-886

3. Menezes CB, Fiorentin B, Bizarro L. Meditação na universidade: a motivação de alunos da UFRGS para aprender meditação. Psicol Esc Educ. 2012;16(2):307-15. doi: 10.1590/S1413-85572012000200014

4. Carneiro, DM. Ayurveda: saúde e longevidade na tradição milenar da Índia. São Paulo: Pensamento; 2009.

5. Barreto VPC, Ferreira SCM, Correia DMS. Estresse ocupacional na enfermagem e mindfulness: o que há de novo? Rev Enferm Atual In Derme [Internet]. 2017 [acesso em 2020 maio 23];80(18):40-6. Disponível em: https://revistaenfermagematual.com.br/index.php/revista/article/view/346/229

6. Schmidt C, Vinet EV. Atención Plena: validación del Five Facet Mindfulness Questionnaire (FFMQ) en estudiantes universitarios chilenos. Ter Psicol. 2015;33(2):93-101. doi: 10.4067/S071848082015000200004

7. Ministério da Saúde (BR). Política nacional de práticas integrativas e complementares no SUS: atitude de ampliação de acesso. Brasília (DF): Ministério da Saúde; 2015.

8. Mendes R, Pezzato LM, Sacardo DP. Pesquisa-intervenção em promoção da saúde: desafios metodológicos de pesquisar “com”. Ciênc Saúde Colet. 2016;21(6):1737-46. doi: http://dx.doi.org/10.1590/1413-81232015216.07392016

9. Minayo MCS, Deslandes SF, Gomes R, organizadores. Pesquisa social: teoria, método e criatividade. Petrópolis: Vozes; 2016.

10. BRASIL. Ministério da Educação. Lei nº 12.711, de 29 de agosto de 2012. Dispõe sobre o ingresso nas universidades federais e nas instituições federais de ensino técnico de nível médio e dá outras providências. Diário Oficial da União: Seção 1, p.1-2. 30 ago. 2012.

11. Cestari VRF, Barbosa IV, Florêncio RS, Pessoa VLMP, Moreira TMM. Stress in nursing students: study on sociodemographic and academic vulnerabilities. Acta Paul Enferm. 2017;30(2):190-6. doi: 10.1590/1982-0194201700029

12. Bresolin JZ, Dalmolin GL, Vasconcellos SJL, Barlem ELD, Andolhe R, Magnago TSBS. Sintomas depressivos em estudantes universitários da área da saúde. Rev Latinoam Enferm. 2020;28:e3239. doi: 
Meditação: uma estratégia de cuidado em saúde para estudantes universitários $\mid 20$

$10.1590 / 1518-8345.3210 .3239$

13. Esper MV, Gnatta JR, Silva MJP. Caracterização da produção científica sobre meditação na área da saúde e na Enfermagem: revisão de literatura. Cad Naturol Ter Complement. 2016;5(8):39-46. doi: http://dx.doi.org/10.19177/cntc.v5e8201639-46

14. Noguchi MS. Meditação, saúde coletiva e fonoaudiologia: um diálogo em construção. Distúrbios Comun [Internet]. 2015 Sept [cited 2019 Nov 12];27(3):542-53. Available from: https://revistas.pucsp.br/dic/article/view/22186

15. Carpena MX, Menezes CB. Efeito da meditação focada no estresse e mindfulness disposicional em universitários. Psic Teor Pesqui. 2018;34:e3441. doi: 10.1590/0102.3772e3441

16. Greeson JM, Juberg MK, Maytan M, James K, Rogers H. A randomized controlled trial of Koru: a mindfulness program for college students and other emerging adults. J Am Coll Health. 2014;62(4):22233. doi: https://doi.org/10.1080/07448481.2014.887571

17. Galvão A, Pinheiro M, Gomes MJ, Ala S. Ansiedade, estresse e depressão relacionado com perturbações do sono-vigília e consumo de álcool em alunos do ensino superior. Rev Port Enferm Saúde Mental. 2017;17(Spec No 5):08-12. doi: 10.19131/rpesm.0160

18. Marchi KC, Bárbaro AM, Miasso AI, Tirapelli CR. Ansiedade e consumo de ansiolíticos entre estudantes de enfermagem de uma universidade pública. Rev Eletrônica Enferm. 2013;15(3):731-9. doi: https://doi.org/10.5216/ree.v15i3.18924

19. Araujo AC, Santana CLA, Kozasa EH, Lacerda SS, Tanaka LH. Efeitos de um curso de meditação de atenção plena em estudantes da saúde no Brasil. Acta Paul Enferm. 2020;33:eAPE20190170. doi: http://dx.doi.org/10.37689/acta-ape/2020ao0170

20. Girad TVN, Feix LF. Mindfulness: concepções teóricas e aplicações clínicas. Hígia Rev Ciênc Saúde Oeste Baiano [Internet]. 2015 [acesso em 2019 nov 22];1(2):94-124. Disponível em: http://fasb.edu.br/revista/index.php/higia/article/download/132/135

21. Gherardi-Donato ECS, Fernandes MNF, Scorsolini-Comin F, Zanetti ACG. Mindfulness: reflexão sobre limites e potencialidades para a assistência de enfermagem. Rev Enferm UFSM [Internet]. 2019 [cited 2019 Nov 22];9(e52):1-21. Available from: https://periodicos.ufsm.br/reufsm/article/view/33058/pdf_1

22. Galvanese ATC, Barros NF, d'Oliveira AFPL. Contribuições e desafios das práticas corporais e meditativas à promoção da saúde na rede pública de atenção primária do Município de são Paulo, Brasil. Cad Saúde Pública. 2017;33(12):e00122015. doi: 10.1590/0102-311x00122016

23. Bond AR, Mason HF, Lemaster CM, Shaw SE, Mullin CS, Holick EA, et al. Embodied health: the effects of a mindbody course for medical students. Med Educ Online. 2018;18(1). doi: 10.3402/meo.v18i0.20699 
24. Assis ASM, Portella CFS, Malva VAS. Contribuições da meditação para a qualidade de vida de $\begin{array}{lllll}\text { adolescentes. } & \text { Cad Naturol Ter } \quad \text { Complement. }\end{array}$ http://dx.doi.org/10.19177/cntc.v5e8201629-37

Editora Científica Chefe: Cristiane Cardoso de Paula

Editora Associada: Daiana Foggiato de Siqueira

\author{
Autor correspondente \\ Luísa Maria Schuh \\ E-mail: luisaschuh@hotmail.com.br \\ Endereço: Rua Padre Anchieta, 98, \\ CEP 89560-190 Videira SC
}

\title{
Contribuições de autoria
}

\section{1 - Luísa Maria Schuh}

Concepção do estudo, análise e interpretação dos dados, revisão final com participação crítica e intelectual no manuscrito.

\section{2 - Fernanda Beheregaray Cabral}

Concepção do estudo, revisão final com participação crítica e intelectual no manuscrito.

\section{3 - Leila Mariza Hildebrandt}

Revisão final com participação crítica e intelectual no manuscrito.

\section{4 - Susane Flores Cosentino}

Concepção do estudo, revisão final com participação crítica e intelectual no manuscrito.

\section{5 - Isabel Cristina Dos Santos Colomé}

Revisão final com participação crítica e intelectual no manuscrito.

\section{Como citar este artigo}

Schuh LM, Cabral FB, Hildebrandt LM, Cosentino SF, Colomé ICS. Meditação: uma estratégia de cuidado em saúde para estudantes universitários. Rev. Enferm. UFSM. 2021 [Acesso em: Ano Mês Dia]; vol.11 e9: 1-21. DOI:https://doi.org/10.5902/2179769243156 